\title{
Struktur Skeleton Sirip Kaudal Kompleks Periophthalmus gracilis
}

\author{
GATOT NUGROHO SUSANTO ${ }^{1}$, FRANSISCA RESSA UTARI ${ }^{2}$ \\ ${ }^{1}$ Prodi Pendidikan Biologi, Fakultas Keguruan dan Ilmu Pendidikan, Universitas Sanata Dharma \\ Kampus III Universitas Sanata Dharma, Jl. Kepuhsari Paingan, Maguwoharjo, Yogyakarta 55282 \\ email: mbahgatotnugroho@gmail.com \\ ${ }^{2}$ Mahasiswa Prodi Pendidikan Biologi, Fakultas Keguruan dan Ilmu Pendidikan, \\ Universitas Sanata Dharma
}

Kampus III Universitas Sanata Dharma, Jl. Kepuhsari Paingan, Maguwoharjo, Yogyakarta 55282

\begin{abstract}
Cauda of Periophthalmus gracilis rarely used for locomotion in land. The objective is to know skeleton structure of caudal fin complex. Skeleton staining used Alizarin red's-alcian blue modified from Inouye (1976). Periophthalmus gracilis's caudal fin complex have 8 os preural centrum, 2 os epural, os parhypural, 5 os hypural and branched lepidotrichia. The caudal used to support movement in land. Periophthalmus gracilis used it for balancing and support in land.
\end{abstract}

Keywords: caudal fin complex, Periophthalmus gracilis, skeleton

\section{INTISARI}

Bagian ekor Periophthalmus gracilis jarang sekali digunakan untuk pergerakan di darat dibandingkan dengan sirip pektoral atau sirip pelviknya. Penelitian ini bertujuan untuk mengetahui struktur skeleton sirip kaudal kompleks pada $P$. gracilis. Pembuatan preparat skeleton menggunakan pewarnaan Alizarin red's-alcian blue berdasarkan pada Inouye (1976) yang dimodifikasi. Hasil penelitian menunjukkan bahwa sirip kaudal kompleks $P$. gracilis memiliki delapan os preural centrum, dua os epural, os parhypural, lima os hypural dan lepidotrichia bercabang. Periophthalmus gracilis menggunakan bagian kauda-nya untuk mendukung pergerakan di darat. Bagian kauda dari $P$. gracilis digunakan sebagai alat penyeimbang dan tumpuan ketika bergerak di darat.

Kata kunci: Periophthalmus gracilis, sirip caudal kompleks, tulang

\section{PENDAHULUAN}

Sirip kaudal pada Teleostei secara umum mengalami modifikasi. Modifikasi tersebut meliputi fusi tulang hypural (pelebaran spina hemalis) serta reduksi dan fusi baik epural (modifikasi spina neuralis) maupun uroneurals (fusi beberapa vertebra). Secara umum Teleostei memiliki hypural yang melebar dan mengarah ke posterior serta mampu mendukung jari-jari sirip di dorsal dan ventral aksis vertebra prekaudal. Pada mudskipper, sirip kaudal memiliki dua epural (Helfman et al., 2009).

Mudskipper menggunakan sirip pektoral, sirip pelvik dan posterior sirip kaudal sebagai alat gerak di darat. Selama bergerak di darat, bagian ekor meruncing dan sirip anal tidak menyentuh substrat untuk mengurangi gesekan. Bagian ekor mudskipper jarang sekali digunakan untuk pergerakan di darat dibandingkan dengan sirip pektoral atau sirip pelvik (Sayer, 2005).

\section{METODE}

Pengambilan Sampel. Periophthalmus gracilis diambil di Pantai Drini, Kecamatan Tepus, Kabupaten Gunungkidul, Yogyakarta.

Pembuatan preparat tulang dan otot. Proses ini dilakukan di Laboratorium Struktur Perkembangan Hewan, Fakultas Biologi, Universitas Gadjah Mada. Pembuatan preparat skeleton menggunakan metode pengecatan Alizarin red-Alcian blue berdasarkan pada Inouye (1976) yang dimodifikasi. Bahan yang diperlukan untuk pembuatan preparat skeleton adalah larutan 
fiksatif berupa alkohol $70 \%$ dan $96 \%$, larutan $1 \% \mathrm{KOH}$, aseton, gliserol serta larutan pewarna menggunakan pewarna Alizarin red's-Alcian blue dapat dibedakan antara tulang dan kartilago. Komposisi larutan pewarna yaitu, 1 volume $03 \%$ larutan alcian blue dalam alkohol $70 \%, 1$ volume $0,1 \%$ larutan alizarin red dalam alkohol 95\%, 1 volume asam asetat glasial dan 2 volume alkohol $70 \%$. Hasil pewarnaan akan menunjukkan bahwa skeleton yang berwarna merah adalah tulang sejati dan berwarna biru adalah kartilago sedangkan otot yang mengelilingi skeleton akan terlihat transparan. Preparat skeleton disimpan dalam gliserol murni. Penamaan skeleton dan otot berdasarkan pada Fujita (1989) dan Lauder (1989).

\section{HASIL}

Tulang kauda pada $P$. gracilis terdiri atas 8 os preural centrum, 2 os epural, os parhypural dan lima os hypural dengan os hypural 1 dan 2 menyatu sedangkan os hypural 3 menyatu dengan os hypural 4. Periophthalmus gracilis memiliki 2 jari-jari sirip kaudal dengan 3 jari tak bersegmen dan tak bercabang serta 14 jari bersegmen dan bercabang. Tujuh jari bersegmen bagian dorsal memiliki 3-4 cabang pada bagian distalnya sedangkan tujuh jari-jari bersegmen pada bagian ventral memiliki 2-3 cabang pada bagian distalnya.

a. Os preural centrum. Periophthalmus gracilis memiliki 8 os preural centrum dengan ujung caudal membentuk urostyle (Gambar 1). Os preural centrum dicirikan dengan terdapatnya pelebaran pada ujung spina neuralis maupun spina hemalis. Pelebaran terluas terdapat pada spina neuralis dan spina hemalis preural kedua. Antar vertebra bagian caudal dihubungkan oleh zygapophysis. Zygapophysis terdiri atas prezygapophysis, tonjolan ke kranial bagian kranial centrum, dan postzygapophysis tonjolan ke kaudal bagian kaudal centrum (Gambar 1D). Pada centrum preural keenam hingga kedelapan terdapat canalis hemalis dan canalis neuralis sedangkan mulai centrum preural kedua hingga kelima tidak terbentuk canal pada bagian neural maupun hemal hanya terbentuk cekungan pada arcus neuralisnya.

b. Os hypural. Periophthalmus gracilis memiliki lima os hypural dengan os hypural pertama berfusi dengan os hypural kedua dan os hypural ketiga berfusi dengan os hypural keempat (Gambar 1A, 2A). Adanya fusi pada os hypural diperlukan untuk memperkuat fungsi os hypural. Os hypural berfungsi untuk menyokong jari-jari sirip kaudal serta seluruh pergerakan sirip kaudal. Pada bagian medial os hypural terdapat tulang yang menyerupai zygapophysis pada vertebra (Gambar 2A). Pada bagian posterior os hypural terdapat os parhypural yang berartikulasi dengan spina hemalis preural kedua (Gambar 2A). Secara umum os parhypural berartikulasi langsung pada urostyle dan berfungsi membantu mengayunkan ekor. Namun pada $P$. gracilis os parhypural menempel pada spina hemalis sehingga kemungkinan fungsinya membantu menghubungkan spina hemalis dengan os hypural ventral bergerak didarat.

c. Os epural. Pada bagian epaksial sirip kaudal $P$. gracilis terdapat dua os epural (Gambar 1A dan 2A). Os epural merupakan modifikasi spina neuralis dan berfungsi untuk menyokong procurrent rays (Helfman et al., 2009). Ukuran os epural pertama lebih besar daripada os epural kedua, hal ini kemungkinan epural pertama merupakan fusi dua epural. Fusi tersebut menyebabkan struktur tulang menjadi kuat sehingga berfungsi menyokong pergerakan (Gambar 1A, 2A).

d. Lepidotrichia. Lepidotrichia sirip kaudal $P$. gracilis memiliki 2 jari-jari dengan 3 jari-jari sirip tidak bersegmen serta 14 jari-jari bersegmen (Gambar 2B dan 2C). Jari-jari bersegmen memiliki cabang pada bagian distal dengan jumlah cabang berbeda antara bagian dorsal dan ventral. Tujuh jari bersegmen bagian dorsal 
memiliki 3-4 cabang pada bagian distal sedangkan tujuh jari-jari bersegmen pada bagian ventral memiliki 2-3 cabang pada bagian distalnya. Formula jari-jari sirip kaudal adalah $2+7+7+1=2$.

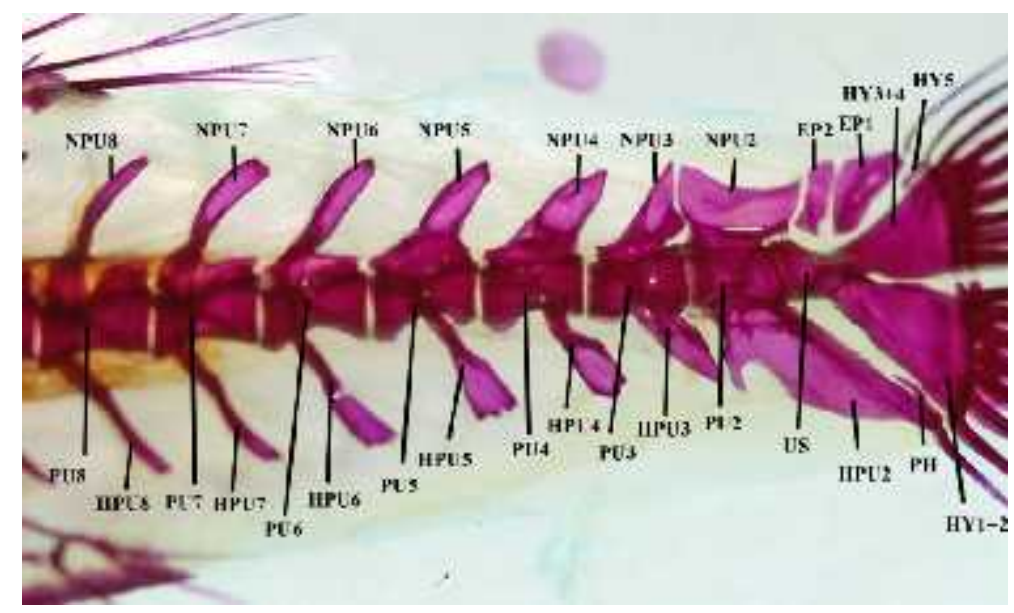

A

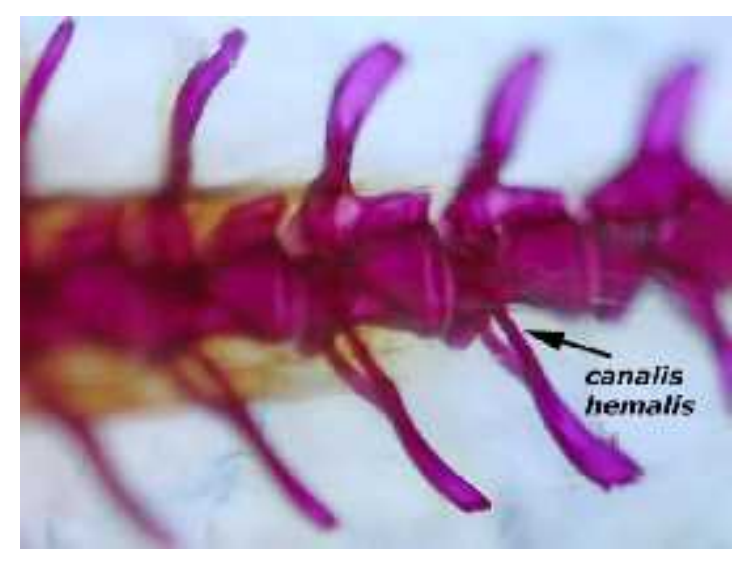

B

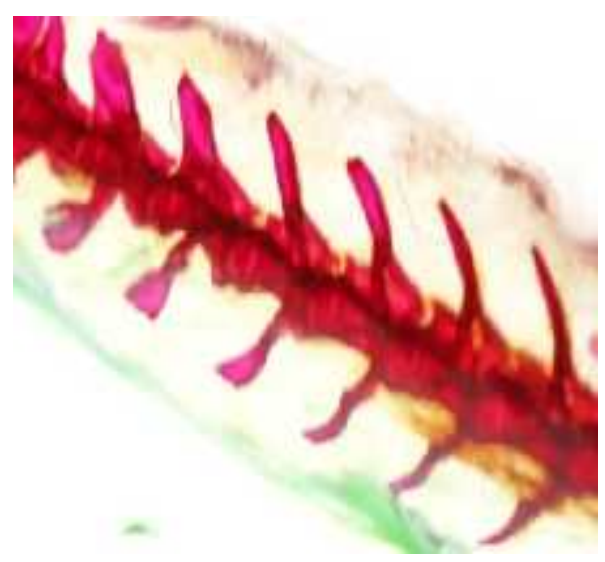

$\mathrm{C}$

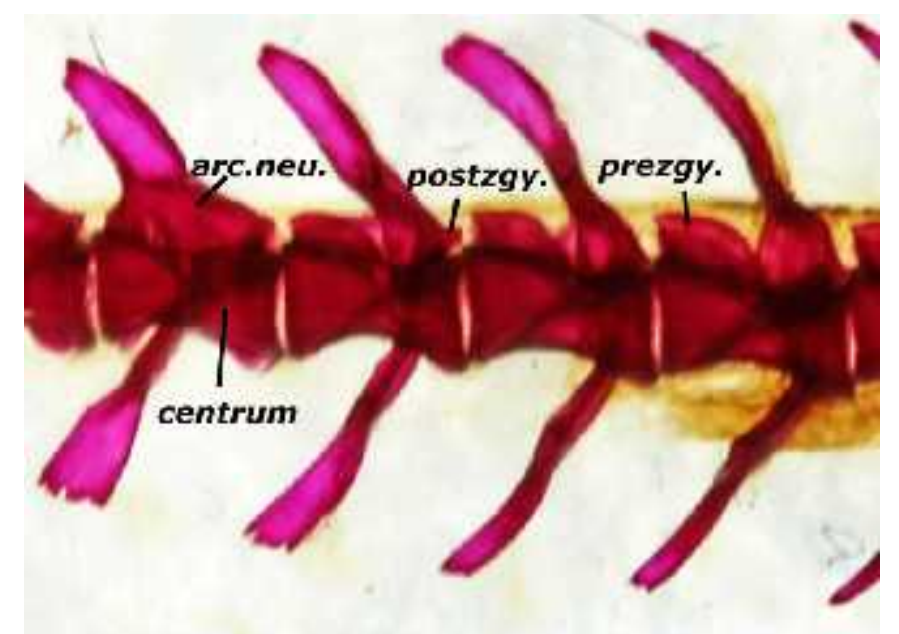

Gambar 1. Elemen tulang kauda P. gracilis. A. Pandangan lateral; B. letak canalis hemalis (anak panah); C. letak canalis neuralis (anak panah) dan D. zygapophysis. EP: epural, HPU: hemal preural, HY: os hypural, NPU: neural preural, PH: os parhypural, PU: os preural centrum, US: urostyle, arc.neu: arcus neuralis, prezgy: prezygapophysis, postzgy: postzygapophysis ( $-: 1 \mathrm{~mm}$ ). 


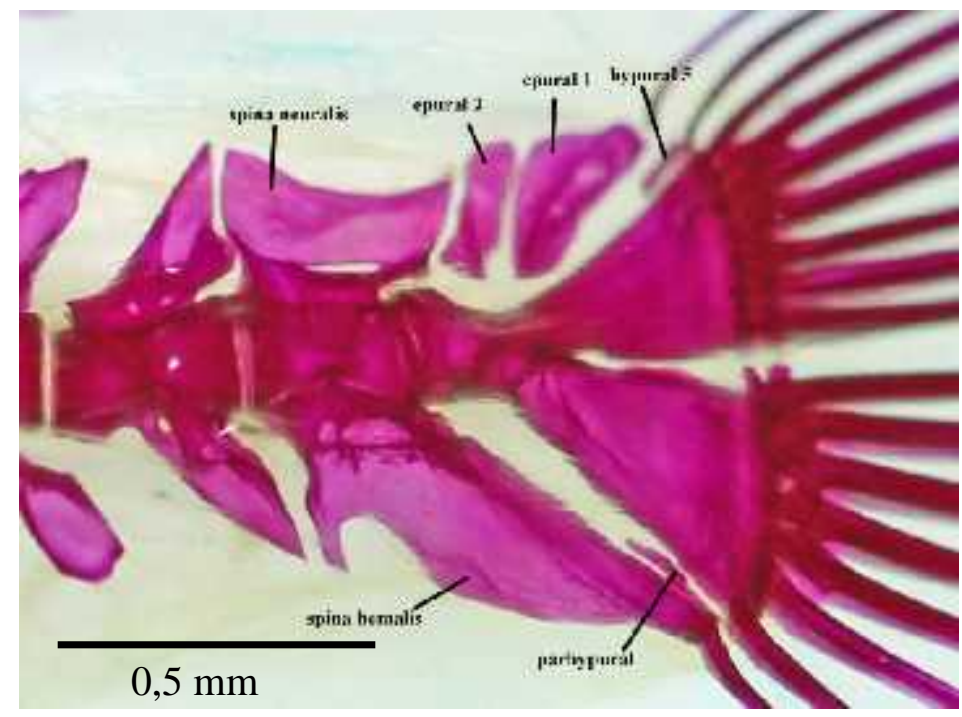

A

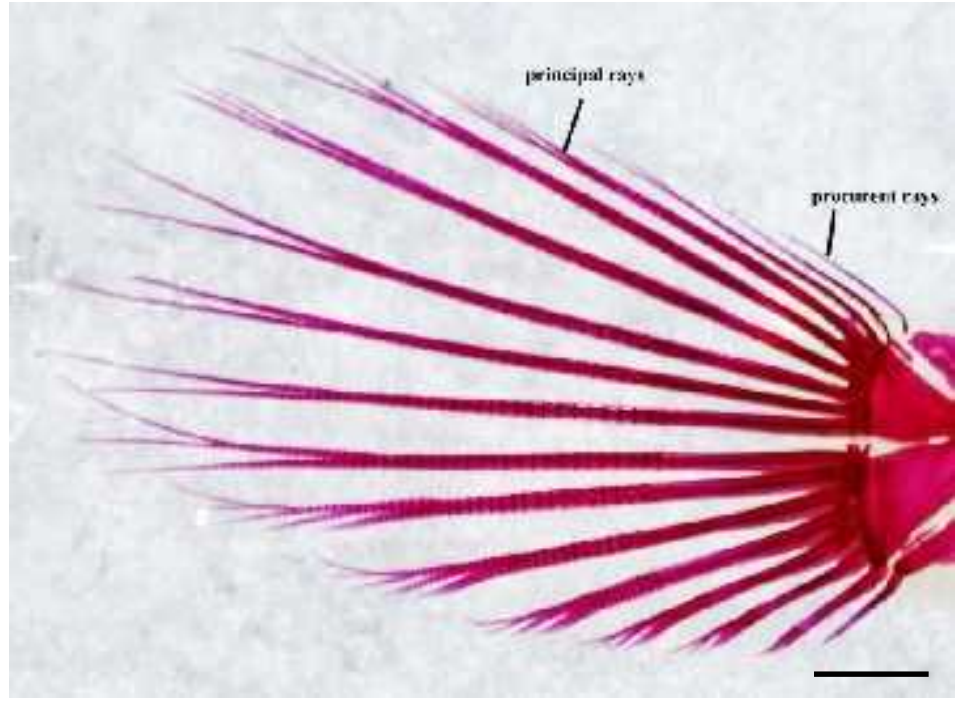

B

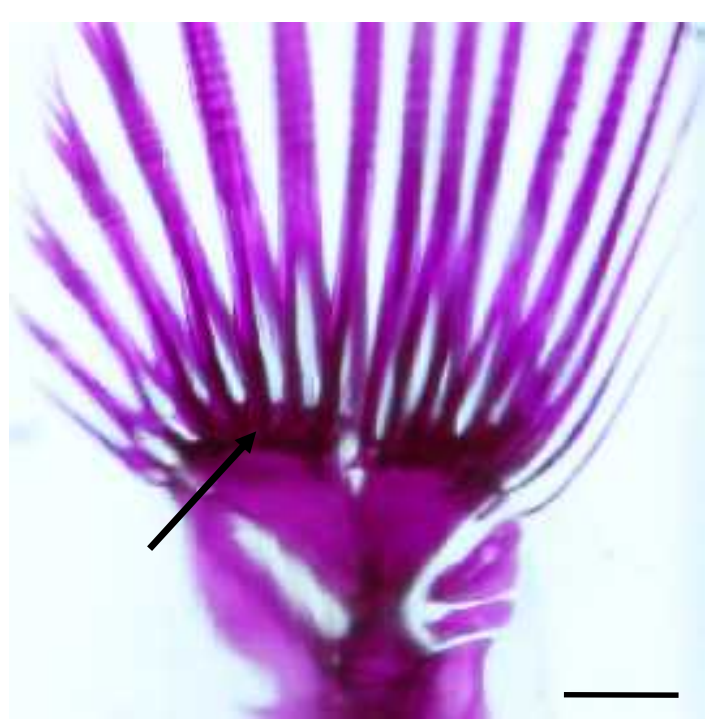

C

Gambar 2. Elemen sirip kaudal dan lepidotricia P. gracilis. A. Letak os parhypural dan epural, anak panah menunjukan letak zygapophysis pada os hypural; B. Jari-jari sirip kaudal dan C. Bentuk proksimal lepidotrichia, anak panah menunjukan lekukan proksimal lepidotricia ( $-: 1 \mathrm{~mm})$.

\section{PEMBAHASAN}

Sirip kaudal $P$. gracilis digunakan sebagai alat lokomosi dan tumpuan ketika ikan ini akan melenting dan bergerak. Bagian ekor dimulai pada vertebra ke-18 dari total 24 vertebra. Pelebaran pada kedua spina di os preural centrum selain sebagai tempat pelekatan otot juga berperan sebagai tumpuan ketika $P$. gracilis berjalan atau pun melenting. Periophthalmus gracilis memerlukan struktur tulang yang kuat dan lebar agar mampu digunakan sebagai alas/tumpuan. Pada beberapa ikan, contohnya ikan tuna dan ikan marlin, zygapophysis digunakan untuk menguatkan persendian antar vertebra. (Hildebrand, 1995).

Adanya bentukan mirip zygapophysis di os hypural memungkinkan dapat menambah kekuatan menempel sehingga tidak akan terjadi dislokasi antar kedua os hypural. Bagian proksimal lepidotrichia berbentuk lekukan dan berartikulasi dengan os hypural sehingga memudahkan jari-jari sirip kaudal berubah bentuk menjadi runcing. Bentukan runcing ini berfungsi sebagai penyeimbang ketika bergerak didarat. Struktur bercabang di 
bagian proksimal lepidotrichia akan memudahkan perubahan jari-jari sirip kaudal.

\section{KESIMPULAN}

Periophthalmus gracilis menggunakan bagian kauda-nya untuk mendukung pergerakan di darat. Bagian kauda dari $P$. gracilis digunakan sebagai alat penyeimbang dan tumpuan ketika bergerak di darat. Hal ini menyebabkan bagian kauda pada $P$. gracilis memiliki struktur skeleton yang kuat dan terdapat modifikasi serta fusi pada tulang penyusunnya.

\section{DAFTAR PUSTAKA}

Fujita K. 1989. Ontogeny of The Caudal Skeleton in the Clariid Catfish Clarias batrachus. Japan. J. Ichthyol. vol 38(4): 430-432.

Helfman GS, Collete BB, Facey DE and Bowen BW. 2009. The diversity of Fishes: Biology, Evolution, and Ecology. Malaysia: A John Wiley \& Sons, Ltd. Publication. pp.33.

Hildebrand M. 1995. Analysis of Vertebrata Structure fourth edition. John Wiley \& Sons, Inc. New York. pp.537.

Inouye, M. 1976. Differential Staining of Cartilage and Bone in Fetal Mouse Skeleton by Alcian Blue and Alizarin Red s. Cong. Anom. 1: 21-23.

Sayer MDJ. 2005. Adaptations of Amphibious Fish for Surviving Life Out of Water. Fish and Fisheries. 6: 200-201. 